\title{
Influence of the level of monovision on visual outcome with an extended range of vision intraocular lens
}

This article was published in the following Dove Press journal:

Clinical Ophthalmology

\section{Béatrice Cochener \\ University Hospital of Brest - Hospital Morvan, Brest, France}

Correspondence: Béatrice Cochener CHRU de Brest - Hôpital Morvan, 2 Avenue Foch 29609 Brest Cedex, France Tel +33 298223497

Fax +33 298223498

Email beatrice.cochener@ophtalmologiechu29.fr
Purpose: The purpose of this study was to evaluate the influence of different levels of monovision on the clinical outcomes achieved with an extended range of vision (ERV) intraocular lens (IOL).

Patients and methods: Subanalysis of 411 patients from the multicenter CONCERTO study aimed at evaluating the outcomes after bilateral implantation of the Tecnis Symfony IOL. Visual acuity, spectacle independence, photic phenomena incidence, and patient satisfaction outcomes were evaluated in six groups defined according to the level of monovision: $0.0 \mathrm{D}$ (75 patients; group 1), $0<\mathrm{x} \leq 0.25 \mathrm{D}$ (148 patients; group 2), $0.25<\mathrm{x} \leq 0.5 \mathrm{D}$ (90 patients; group 3), $0.5<\mathrm{x} \leq 0.75 \mathrm{D}$ (52 patients; group 4), $0.75<\mathrm{x} \leq 1.0 \mathrm{D}$ (27 patients; group 5), and $>1.0 \mathrm{D}$ (19 patients; group 6).

Results: Mean binocular uncorrected distance visual acuity (decimal) ranged from $0.90 \pm 0.17$ in group 6 to $0.97 \pm 0.20$ in group 2. Mean binocular uncorrected intermediate visual acuity (decimal) ranged from $0.77 \pm 0.25$ in group 2 to $0.94 \pm 0.30$ in group 4 . Mean binocular uncorrected near visual acuity ranged from $0.64 \pm 0.23$ in group 2 to $0.79 \pm 0.26$ in group 6 . The level of spectacle independence was high, with the highest value for near vision in group $6(94.7 \%)$. Less patients reported halos $(6.7 \%)$ in group 1 , whereas only $3.8 \%$ of patients in group 4 reported disturbing glare symptoms. For near vision, the highest patient satisfaction was achieved in groups 4, 5, and 6 . A total of $96.7 \%$ (group 3) and $96.2 \%$ (group 4) of patients would recommend the same procedure to their friends and family and would choose the same lens again.

Conclusion: Mini-monovision of around 0.75 D after implantation of the Tecnis Symfony IOL provides a complete visual rehabilitation with minimal photic phenomena and high levels of patient satisfaction.

Keywords: Tecnis Symfony IOL, CONCERTO study, targeted monovision, visual acuity, residual refraction

\section{Introduction}

A new concept of presbyopia-correcting intraocular lens (IOL) technology, extended range of vision (ERV) IOLs, has been recently developed, aiming to minimize photic phenomena, which are commonly related to refractive and diffractive multifocal IOLs while maintaining the achievement of a functional range of vision. ${ }^{1-3}$ It is inherent to multifocal IOLs that for each focal point, secondary out-of-focus images corresponding to the other foci produce halos. The type and intensity of these visual symptoms depend on the lens design, especially on the magnitude of the addition, and pupil size. ${ }^{4}$ Indeed, several clinical studies have reported significant rates of photic phenomena after implantation of different types of multifocal IOLs. ${ }^{5-8}$ In contrast, ERV IOLs are 
designed to provide a continuous range of functional vision without a distinct asymmetric distribution of light to the foci, avoiding secondary out-of-focus images. This can be achieved by using an aspheric achromatic IOL optic ${ }^{9}$ which allows the simultaneous correction of spherical and chromatic aberration, which is the basis of the commercially available Tecnis Symfony IOL (Johnson \& Johnson Vision, Santa Ana, CA, USA).

Clinical studies with the Tecnis Symfony IOL have shown excellent distance and intermediate visual outcomes, with minimal incidence of photic phenomena and high levels of patient satisfaction. ${ }^{1-3}$ Near visual outcomes have been found to be more limited, but still provide functional reading capabilities. ${ }^{1-3}$ A subanalysis of the international CONCERTO multicenter study evaluated the potential benefit of introducing some level of monovision to improve near visual outcome and spectacle independence, with a significant increase in satisfaction score for near vision using the mini-monovision approach. ${ }^{1}$ To our knowledge, the ideal magnitude of monovision, that is, the level of the difference in spherical equivalent (SEQ) between the eyes of a patient, has not yet been investigated. The aim of the current study was to evaluate the impact of different levels of monovision on clinical outcomes and patient satisfaction after the bilateral implantation of the ERV IOL Tecnis Symfony.

\section{Patients and methods}

\section{Patients}

This study is a subanalysis of the results of the multicenter CONCERTO study evaluating the clinical outcomes after bilateral implantation of the Tecnis Symfony IOL. ${ }^{1}$ Patients from 40 active study sites from Finland, France, Germany, Norway, Spain, Sweden, and United Kingdom were included. Inclusion criteria comprised of visually significant cataract, bilateral implantation of the Tecnis Symfony IOL, age $\geq 18$ years, and a postoperative corneal astigmatism of $\leq 0.75$ D. Exclusion criteria were a potential visual acuity $<0.2 \log$ MAR due to ocular pathological processes, systemic or ocular medication that could affect vision, any chronic or acute pathology that could alter the result, previous ocular surgery, amblyopia, strabismus, form frustre or clinical keratoconus, pupil abnormalities, capsular, or zonular abnormalities with the potential of inducing IOL decentration or tilting and participation in another clinical study. This study was performed as a retrospective/ prospective study: Patients were enrolled consecutively after bilateral implantation of the Tecnis Symfony IOL. The last preoperative patient visit and the surgery were documented retrospectively and the 4-8 week and 4-6 month follow-up visits prospectively.

Whereas the study design of the CONCERTO study differentiated between patients targeted for monovision and no-monovision, the current evaluation is based on the stratification for the achieved level of monovision at 4-6 months after surgery. The total sample was divided into six groups according to the postoperative magnitude of monovision (difference in SEQ between both eyes): $0 \mathrm{D}$ (group 1), $0<\mathrm{x} \leq 0.25 \mathrm{D}$ (group 2), $0.25<\mathrm{x} \leq 0.5 \mathrm{D}$ (group 3), $0.5<x \leq 0.75 \mathrm{D}$ (group 4), $0.75<\mathrm{x} \leq 1.0 \mathrm{D}$ (group 5), and $>1.0 \mathrm{D}$ (group 6). In all patients with an intended induction of monovision, the myopic target was always attributed to the non-dominant eye.

The study adhered to the tenets of the Declaration of Helsinki and was approved by the ethics committee (Ethics Committee of the Center Hospitalier Regional Universitaire de Brest). All patients provided written informed consent regarding their participation in the study.

\section{Preoperative and postoperative examinations}

A complete preoperative ophthalmological examination was performed in all cases including measurement of uncorrected (UDVA) and corrected distance visual acuity (CDVA), manifest refraction, Goldmann tonometry, slit lamp anterior segment examination, optical biometry, keratometry, and fundus examination under pupil dilation. Postoperative follow-up examinations were performed 4-8 weeks and 4-6 months after surgery. The following parameters were evaluated: binocular UDVA and monocular and binocular CDVA, binocular uncorrected near visual acuity (UNVA) measured at $40 \mathrm{~cm}$, and binocular uncorrected intermediate visual acuity (UIVA) measured at $70 \mathrm{~cm}$. Likewise, patients were asked about their spectacle use after surgery (how often do you need spectacles to see at far/intermediate/near distances), categorizing the answer into $0 \%, 25 \%, 50 \%, 75 \%$, and $100 \%$ of time. Furthermore, patients were also asked about the incidence of photic phenomena, including halo, glare, starburst, and others (none/ mild, moderate, and severe). Finally, patients were asked about their satisfaction with the procedure and the outcomes: "How satisfied are you with your spectacle free vision at far/intermediate/near distance?" (answers on a scale from "0: not at all satisfied" to "10: very satisfied"), "Would you choose the same lens again?" (Yes/No), and "Would 
you recommend this lens to your relatives and friends?" (Yes/No). The current evaluation is based on the results at the 4-6 months follow-up visit.

\section{Surgery}

All surgeries were performed by experienced surgeons from the CONCERTO study group using a standard technique of phacoemulsification. Incisions were performed in all cases at the temporal area. All procedures were performed under topical anesthesia and after instilling mydriatic drops several minutes before the surgery. The IOLs were inserted into the capsular bag using the UNFOLDER Platinum 1 Series Screw-Style Inserter (Johnson \& Johnson Vision) through the main incision. Postoperative care followed the routine procedure of each study site.

\section{Data analysis}

Means and SDs with CIs (95\%) were calculated for binocular UDVA, UIVA, and UNVA for each group. Likewise, percentages corresponding to each answer of questions about patient satisfaction, spectacle independence, and photic phenomena were determined for each group. SPSS statistics software package version 15.0 for Windows (SPSS Inc., Chicago, IL, USA) was used for these analyses.

\section{Results}

A total of 411 patients (246 females, 165 males) with a mean age of $66.5 \pm 10.9$ years were included in this analysis. The following number of patients was included in each monovision group: 75 patients in group 1, 148 patients in group 2,
90 patients in group 3, 52 patients in group 4, 27 patients in group 5, and 19 patients in group 6 (Table 1).

\section{Visual outcomes and spectacle independence}

The pre- and postoperative visual acuity and refraction data are shown in Table 1.

Mean postoperative binocular decimal UDVA ranged from $0.90 \pm 0.17$ in group 6 to $0.97 \pm 0.20$ in group 2 (Figure 1). Likewise, mean binocular decimal UIVA ranged from $0.77 \pm 0.25$ in group 2 to $0.94 \pm 0.30$ in group 4 (Figure 1). Mean postoperative binocular UNVA values ranged from $0.64 \pm 0.23$ in group 2 to $0.79 \pm 0.26$ in group 6 (Figure 1 ). The level of spectacle independence reported by patients was high, with most of them not requiring spectacles for distance, intermediate, or near visual activities, as shown in Figure 2. For a monovision level of $>1.00 \mathrm{D}$, none of the patients needed spectacles for intermediate distance and $94.7 \%$ were spectacle-independent for near distances (Figure 2). In contrast, from the eyes without monovision, $84.0 \%$ and $76.0 \%$ of patients were independent from spectacles for performing intermediate and near visual tasks, respectively (Figure 2).

\section{Photic phenomena}

Halos were absent or only occasionally present in most of the patients, with percentages ranging from $93.3 \%$ in group 1 to $78.9 \%$ in group 6 (Figure 3 ). The percentage of eyes with no or occasional glare ranged from $96.2 \%$ in group 4 to $78.9 \%$ in group 6 (Figure 3). Regarding starbursts, the incidence was relatively equal between the groups with the highest

Table I Pre- and postoperative visual acuity and refraction

\begin{tabular}{|c|c|c|c|c|c|c|}
\hline Parameter & Group I & Group 2 & Group 3 & Group 4 & Group 5 & Group 6 \\
\hline Number of patients & 75 & 148 & 90 & 52 & 27 & 19 \\
\hline $\begin{array}{l}\text { Age (years) } \\
\text { Mean } \pm \text { SD }\end{array}$ & $66.31 \pm 10.19$ & $65.64 \pm 12.05$ & $67.26 \pm 9.39$ & $66.71 \pm 10.70$ & $67.19 \pm 10.28$ & $68.32 \pm 11.42$ \\
\hline Gender (n) & $\begin{array}{l}\text { F: } 46 \\
\text { M: } 29\end{array}$ & $\begin{array}{l}\text { F: } 84 \\
\text { M: } 64\end{array}$ & $\begin{array}{l}\text { F: } 58 \\
\text { M: } 32\end{array}$ & $\begin{array}{l}\text { F: } 29 \\
\text { M: } 23\end{array}$ & $\begin{array}{l}\text { F: } 17 \\
\text { M: } 10\end{array}$ & 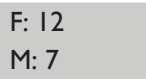 \\
\hline Preoperative SEQ (D), mean \pm SD & $0.47 \pm 2.28$ & $0.17 \pm 3.06$ & $0.14 \pm 3.30$ & $0.69 \pm 2.32$ & $0.24 \pm 2.06$ & $0.37 \pm 3.65$ \\
\hline Preoperative CDVA, monocular (decimal), mean \pm SD & $0.68 \pm 0.28$ & $0.69 \pm 0.26$ & $0.7 I \pm 0.25$ & $0.74 \pm 0.31$ & $0.67 \pm 0.30$ & $0.62 \pm 0.23$ \\
\hline Preoperative CDVA, binocular (decimal), mean \pm SD & $0.77 \pm 0.25$ & $0.77 \pm 0.25$ & $0.77 \pm 0.25$ & $0.8 \mathrm{I} \pm 0.34$ & $0.74 \pm 0.29$ & $0.68 \pm 0.22$ \\
\hline Postoperative SEQ (D), mean \pm SD & $-0.24 \pm 0.36$ & $-0.2 I \pm 0.44$ & $-0.34 \pm 0.45$ & $-0.4 I \pm 0.57$ & $-0.55 \pm 0.67$ & $-0.83 \pm 0.96$ \\
\hline $\begin{array}{l}\text { Postoperative UDVA, binocular (decimal), mean } \pm \text { SD } \\
95 \% \mathrm{Cl}\end{array}$ & $\begin{array}{l}0.93 \pm 0.19 \\
0.89-0.97\end{array}$ & $\begin{array}{l}0.97 \pm 0.20 \\
0.94-1.00\end{array}$ & $\begin{array}{l}0.95 \pm 0.19 \\
0.91-0.99\end{array}$ & $\begin{array}{l}0.96 \pm 0.25 \\
0.89-1.03\end{array}$ & $\begin{array}{l}0.92 \pm 0.20 \\
0.84-1.00\end{array}$ & $\begin{array}{l}0.90 \pm 0.17 \\
0.82-0.98\end{array}$ \\
\hline $\begin{array}{l}\text { Postoperative UIVA, binocular (decimal), mean } \pm \text { SD } \\
95 \% \mathrm{CI}\end{array}$ & $\begin{array}{l}0.83 \pm 0.26 \\
0.77-0.89\end{array}$ & $\begin{array}{l}0.77 \pm 0.25 \\
0.73-0.81\end{array}$ & $\begin{array}{l}0.78 \pm 0.26 \\
0.73-0.83\end{array}$ & $\begin{array}{l}0.94 \pm 0.30 \\
0.86-1.02\end{array}$ & $\begin{array}{l}0.91 \pm 0.24 \\
0.82-1.00\end{array}$ & $\begin{array}{l}0.85 \pm 0.30 \\
0.72-0.98\end{array}$ \\
\hline $\begin{array}{l}\text { Postoperative UNVA, binocular (decimal), mean } \pm \text { SD } \\
95 \% \mathrm{Cl}\end{array}$ & $\begin{array}{l}0.68 \pm 0.24 \\
0.63-0.73\end{array}$ & $\begin{array}{l}0.64 \pm 0.23 \\
0.60-0.68\end{array}$ & $\begin{array}{l}0.67 \pm 0.25 \\
0.62-0.72\end{array}$ & $\begin{array}{l}0.78 \pm 0.22 \\
0.72-0.84\end{array}$ & $\begin{array}{l}0.78 \pm 0.28 \\
0.67-0.89\end{array}$ & $\begin{array}{l}0.79 \pm 0.26 \\
0.67-0.9 \mid\end{array}$ \\
\hline
\end{tabular}

Abbreviations: CDVA, corrected distance visual acuity; F, female; M, male; SEQ, spherical equivalent; UDVA, uncorrected distance visual acuity; UIVA, uncorrected intermediate visual acuity; UNVA, uncorrected near visual acuity. 


\section{Influence of the magnitude of monovision on binocular visual acuity}

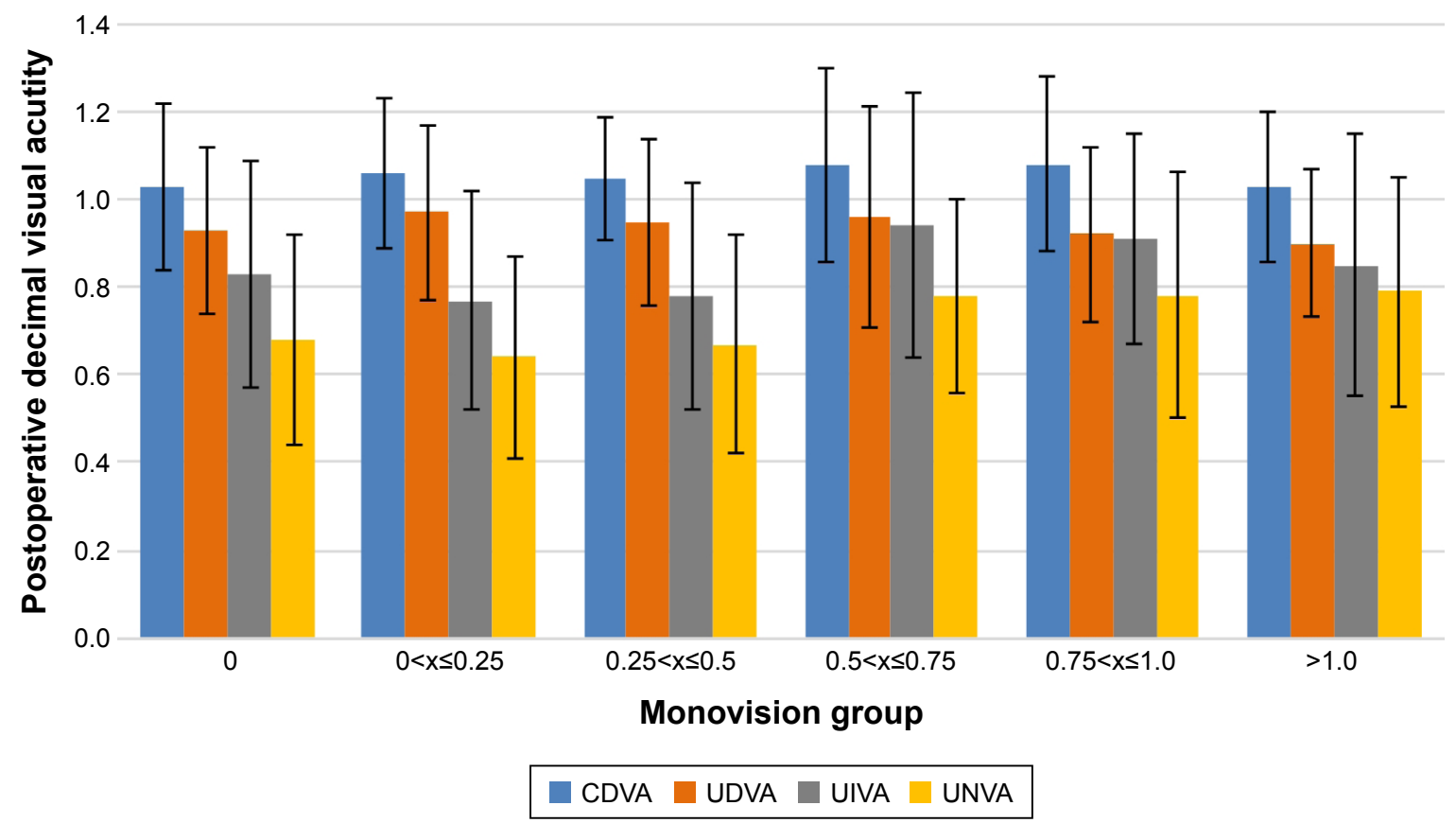

Figure I Distance, intermediate, and near visual outcomes for different levels of monovision.

Note: Data are displayed as means with SD.

Abbreviations: CDVA, corrected distance visual acuity; UDVA, uncorrected distance visual acuity; UIVA, uncorrected intermediate visual acuity; UNVA, uncorrected near visual acuity.

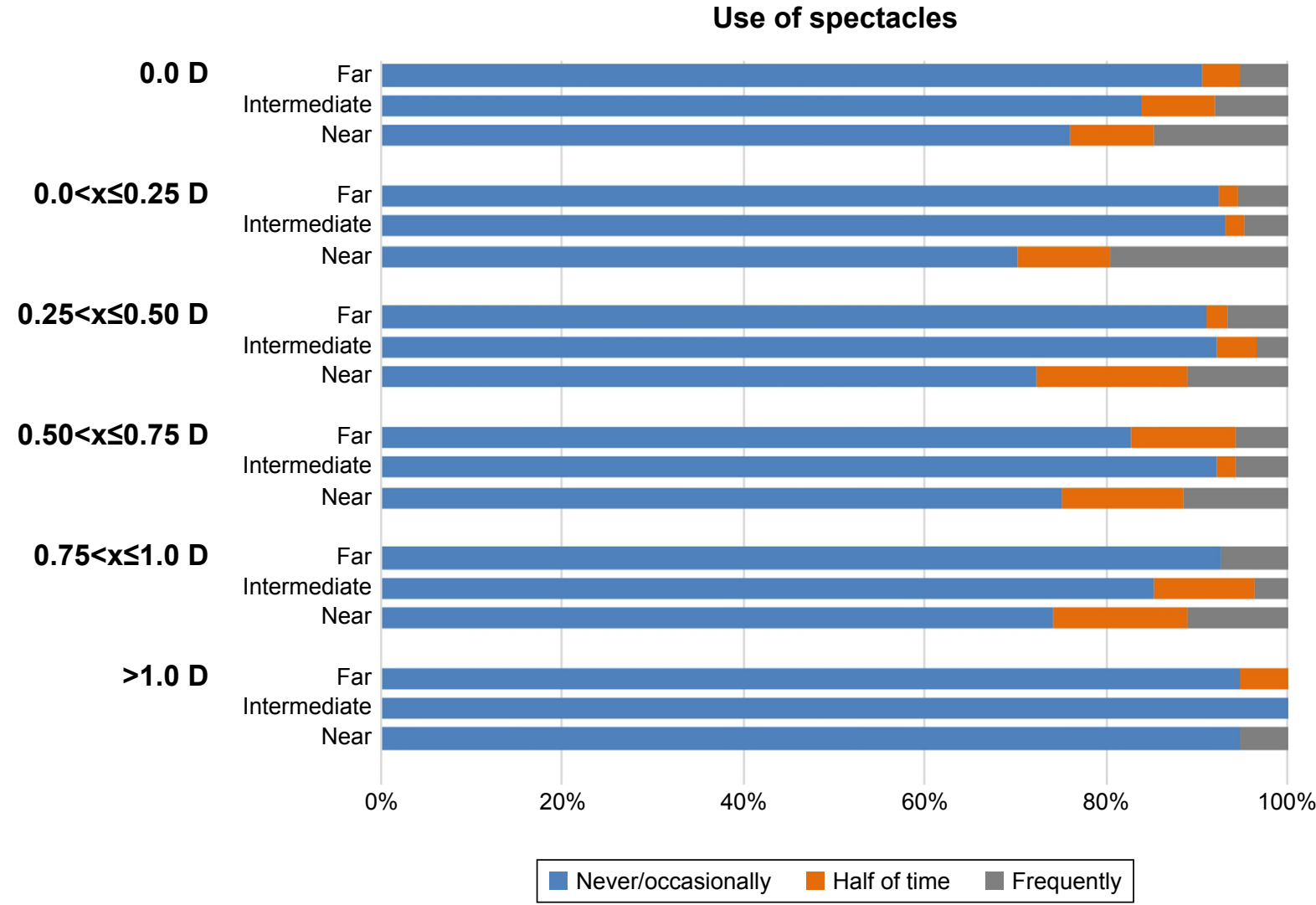

Figure 2 Postoperative spectacle independence for near, intermediate, and distance vision tasks at different levels of monovision. 


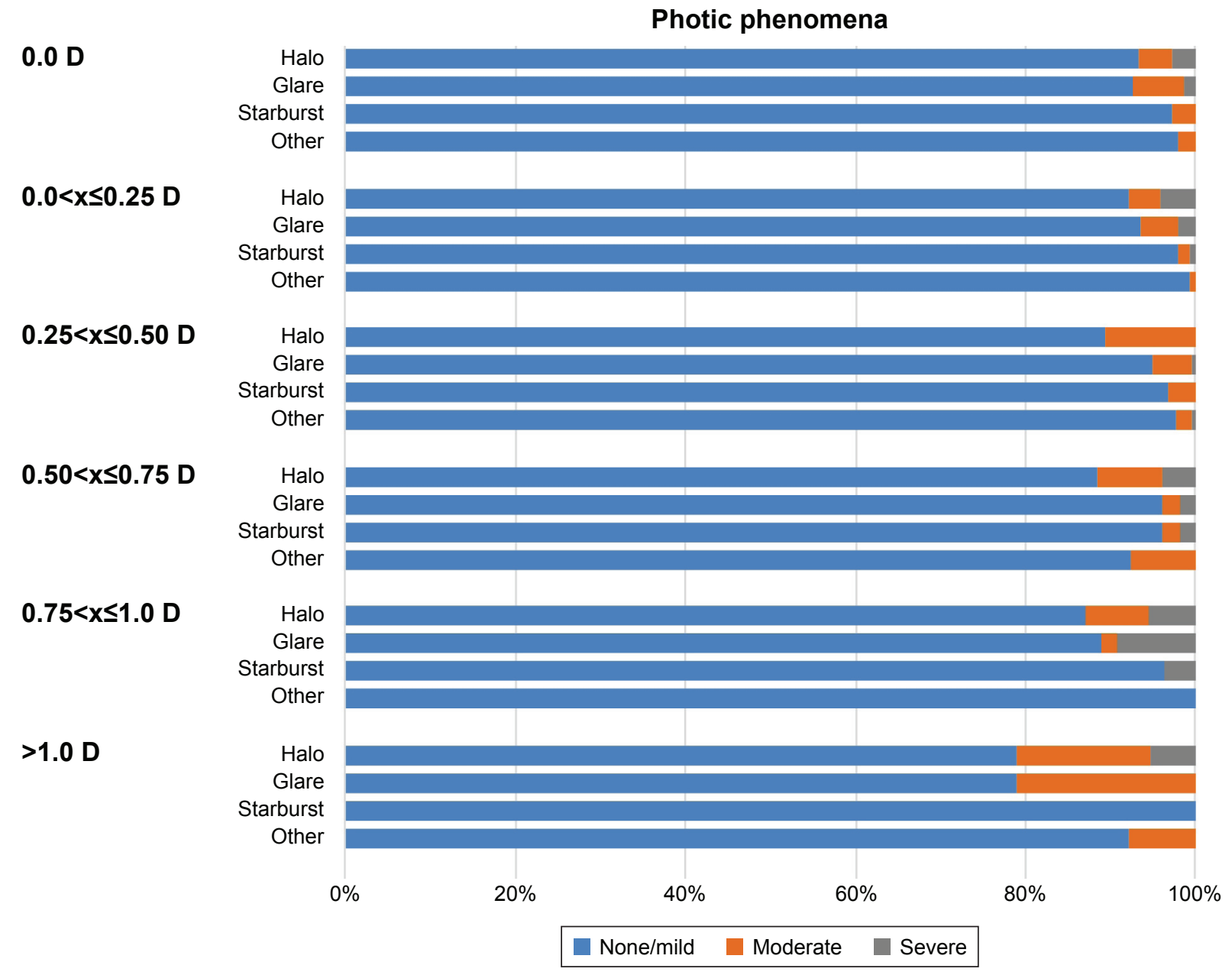

Figure 3 Postoperative incidence of photic phenomena at different levels of monovision.

percentage of severe presence of this photic phenomenon in group 5 (3.7\%) (Figure 3).

\section{Patient satisfaction}

Similar median patient satisfaction scores were obtained for distance vision in all monovision groups (Figure 4). For intermediate distance, the best median scores were obtained in lower monovision groups ( 2 and 3 ) and in group 6. For near vision, the best satisfaction outcomes were obtained in groups 4, 5, and 6 (Figure 4).

A total of $96.7 \%$ (group 3) and $96.2 \%$ (group 4) of patients would recommend the same procedure to their friends and family and would choose the same lens again (Figure 5) with lower percentages for the rest of monovision groups (Figure 5).

\section{Discussion}

The ERV IOL Tecnis Symfony has demonstrated to provide functional distance, intermediate and near visual acuity, with excellent results for distance and intermediate vision and some limitation for near vision. ${ }^{1-3}$ This limitation has been suggested to be overcome with a mini-monovision approach by the induction of some level of residual myopia in the non-dominant eye. ${ }^{1}$ However, the magnitude of induced myopia for optimization of the visual outcome is not yet known for the investigated IOL. In the current study, we performed a subanalysis of the CONCERTO multicenter study data and stratified the evaluation for the magnitude of monovision. With monofocal IOLs, a monovision around $0.75 \mathrm{D}$ was shown to induce good distance ( $100 \%$ achieving at least $0.0 \log$ MAR binocular UDVA) and intermediate visual outcome $(100 \%$ achieving at least $0.1 \log$ MAR binocular UIVA), and a relatively functional near vision (63.33\% achieving $0.3 \log$ MAR binocular UNVA). ${ }^{10}$ Less dependence on glasses has been reported for multifocal IOLs compared to pseudophakic monovision, but with significantly more photic phenomena and an increased risk for IOL explantation due to patient dissatisfaction. ${ }^{11-15}$ Hence, 


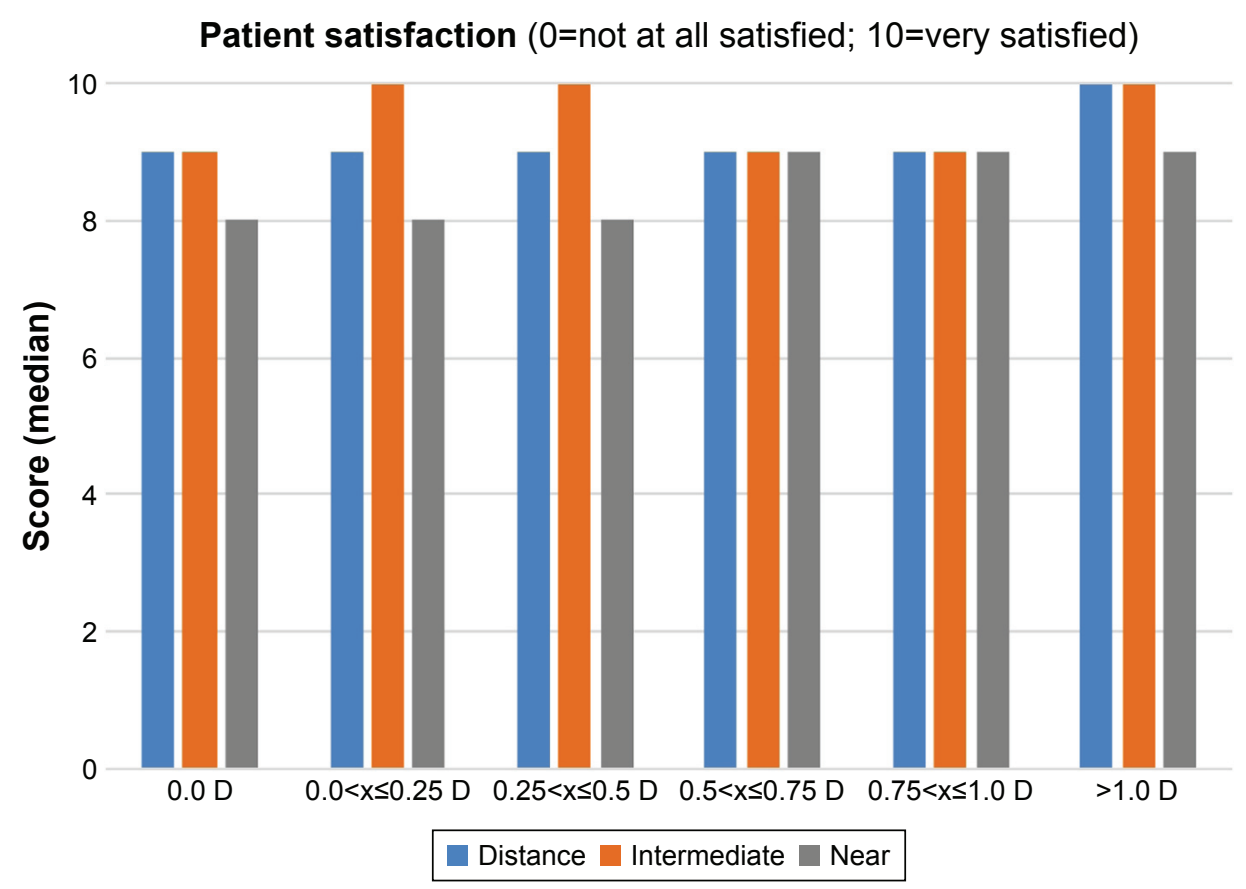

Figure 4 Patient satisfaction with distance, intermediate, and near vision after implantation of the Tecnis Symfony IOL on a scale from 0 (not at all satisfied) to 10 (very satisfied) at different levels of monovision.

monovision using monofocal IOLs with modest refractive differences between eyes is able to provide functional vision and good patient satisfaction without the inherent risk for troublesome visual symptoms associated with multifocal IOLs. ${ }^{10-15}$ Our hypothesis was that the use of an ERV IOL with a mini-monovision approach may be an effective option for a complete visual rehabilitation, as ERV IOLs provide excellent distance and intermediate visual outcomes and the minimal limitation for near vision may be overcome with the induced slight monovision.

Our study revealed that although UDVA showed no clinically relevant difference among groups, UIVA worsened at the highest levels of monovision, suggesting that monovision levels between 0.50 and $0.75 \mathrm{D}$ may be the recommendable

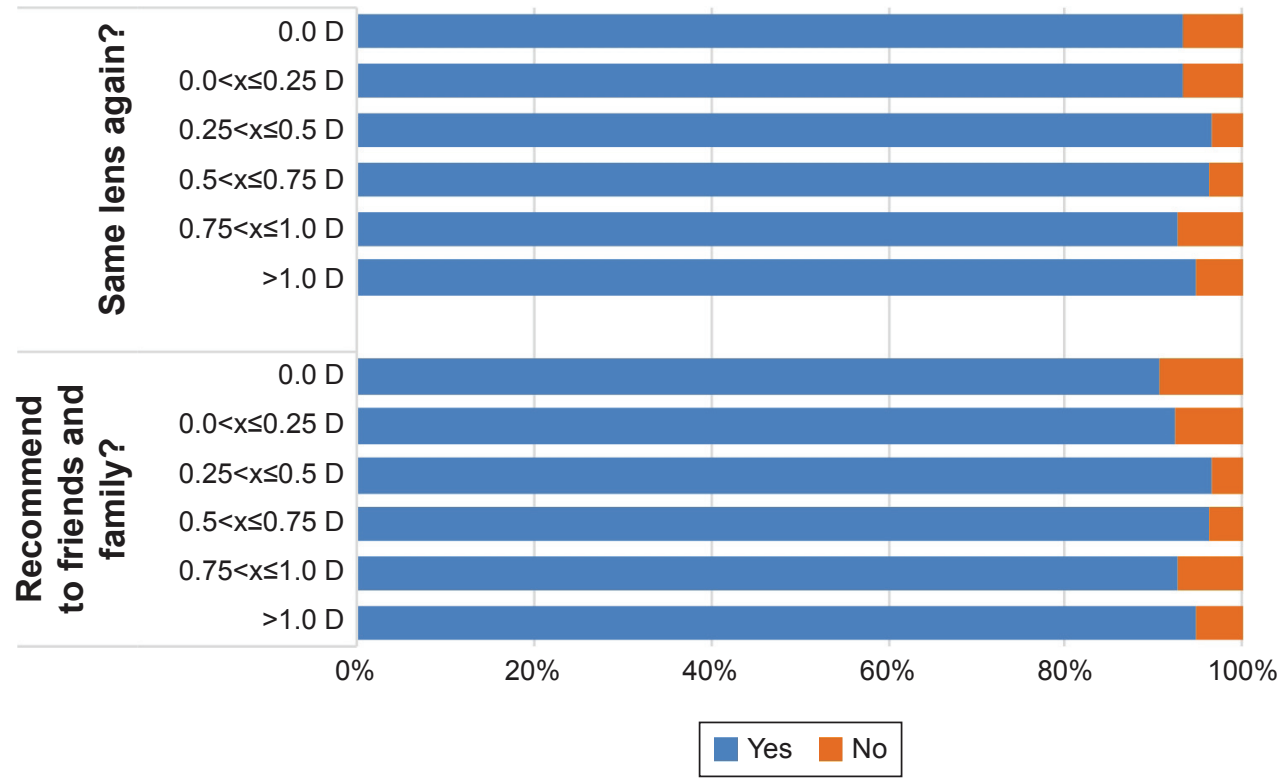

Figure 5 Percentage of patients who would recommend the same procedure to their friends and family and who would choose the same lens again for different levels of monovision. 
option. In contrast, better UNVA was obtained with higher levels of monovision as in groups 4,5 , and 6 , with the best outcome with the induction of anisometropias $>1.0 \mathrm{D}$ (mean value: $0.79 \pm 0.26$ decimal, equivalent to $0.1 \log$ MAR or J1 on the Jaeger scale). This level of near visual outcome is better than that reported for pseudophakic mini-monovision correction with monofocal IOLs. ${ }^{10,11,13-15}$ Our mini-monovision results were comparable to those with multifocal IOLs, but with a lower incidence of photic phenomena., ${ }^{76-19}$ According to the results of our study, a monovision around $0.75 \mathrm{D}$ seems to be the most recommendable option as it improved near vision without degradation of distance and intermediate vision. This option also provided high levels of spectacle independence at near $(75.0 \%$ in group $4,74.1 \%$ in group 5$)$, which was better than spectacle independence levels reported for mini-monovision approaches with monofocal IOLs. ${ }^{10,11,13,15}$ Likewise, this level of spectacle independence was equivalent to that found with some multifocal IOLs. ${ }^{16,17}$

Besides good visual and spectacle independence outcomes, monovision levels around $0.75 \mathrm{D}$ were also found to provide low incidence of halos and glare, with $88.5 \%$ and $96.2 \%$, respectively, not reporting them at all or reporting them only occasionally. This incidence is minimal compared to the dissatisfaction rates and patient complaints due to these phenomena observed with multifocal IOLs. ${ }^{20,21}$ Indeed, significantly higher rates of photic phenomena have been reported for different types of multifocal IOLs. ${ }^{7,16-19,21}$ It should be considered that significant disturbances due to photic phenomena are one of the main causes for multifocal IOL explantations. ${ }^{22}$ Lubiński et $\mathrm{al}^{21}$ found that $75 \%$ of patients implanted with a diffractive bifocal IOL reported the perception of some level of halos. Law et $\mathrm{al}^{7}$ found in a group of eyes implanted with a trifocal IOL that $80 \%$ of patients reported difficulties associated with halo perception at 1 month postoperatively, but this percentage decreased to $40 \%$ at 6 months after surgery. Similarly, these authors also demonstrated a reduction in the difficulties associated with glare perception over time, with the percentage decreasing from $73.3 \%$ at 1 month to $13.3 \%$ at 6 months postoperatively. ${ }^{7}$ Finally, concerning patient satisfaction, the best outcome for near vision satisfaction was obtained for monovision levels $>0.50 \mathrm{D}$, while maintaining high levels of satisfaction with distance and intermediate vision. For a monovision level between 0.51 and 0.75 D, 96.2\% of patients would recommend the same procedure to their friends and family and would choose the same lens again. This high level of patient satisfaction is in agreement with the outcome reported in other studies evaluating the results of pseudophakic micro-monovision with monofocal IOLs. ${ }^{10,11,15}$ Zettl et $\mathrm{al}^{10}$ found a high patient satisfaction score of 93.18 in the VF-14 questionnaire after the implantation of monofocal IOLs generating an anisometropia between 0.5 and $1.75 \mathrm{D}$. Likewise, the level of patient satisfaction achieved in our study with the ERV IOL and a monovision of around $0.75 \mathrm{D}$ is also consistent with that reported for different multifocal IOLs. ${ }^{7,16,17,19}$ Mendicute et $\mathrm{l}^{16}$ found that more than $90 \%$ of patients implanted with a trifocal diffractive IOL were satisfied with the visual outcome. Kretz et $\mathrm{al}^{17}$ found that $100 \%$ of patients implanted with a bifocal diffractive IOL were at least moderately happy with the outcomes of the surgery.

\section{Conclusion}

We found the overall best results in monovision levels of 0.5 to $\leq 0.75 \mathrm{D}$ and 0.75 to $\leq 1.0 \mathrm{D}$, which indicates that a mini-monovision of around $0.75 \mathrm{D}$ in eyes implanted bilaterally with the ERV IOL Tecnis Symfony may provide the optimum visual rehabilitation after cataract surgery, with good levels of visual acuity across all distances, minimal incidence of photic phenomena, and high levels of patient satisfaction. Monovision levels $>0.75 \mathrm{D}$ resulted in slightly worse intermediate visual acuity. Future studies should evaluate the impact of mini-monovision on stereopsis and the long-term outcome with this approach.

\section{Acknowledgments}

This paper was presented at the ESCRS 2017 as a poster with interim findings. The free paper abstract was published on the ESCRS website: http://www.escrs.org/Lisbon2017/ programme/free-papers-details .asp? $i d=28213 \&$ day $=0$. The study was sponsored by Johnson \& Johnson Vision who also covers the processing charge of this article.

\section{Disclosure}

Dr Cochener is a clinical investigator for Revision Optics, Inc., Horus Vision LLC, Alcon Laboratories, Inc., Johnson \& Johnson Vision, Inc., Thea Pharma GmbH, and Santen, Inc.; she is also a consultant to Alcon Laboratories, Inc., Johnson \& Johnson Vision, Inc., Thea Pharma GmbH, and Santen, Inc.

\section{References}

1. Cochener B, Concerto Study Group. Clinical outcomes of a new extended range of vision intraocular lens: International Multicenter Concerto Study. J Cataract Refract Surg. 2016;42(9):1268-1275.

2. Pedrotti E, Bruni E, Bonacci E, Badalamenti R, Mastropasqua R, Marchini G. Comparative Analysis of the Clinical Outcomes With a Monofocal and an Extended Range of Vision Intraocular Lens. J Refract Surg. 2016;32(7):436-442. 
3. Kaymak H, Höhn F, Breyer DR, et al. Functional Results 3 Months after Implantation of an "Extended Range of Vision" Intraocular Lens. Klin Monbl Augenheilkd. 2016;233(8):923-927.

4. Vega F, Alba-Bueno F, Millán MS, Varón C, Gil MA, Buil JA. Halo and Through-Focus Performance of Four Diffractive Multifocal Intraocular Lenses. Invest Ophthalmol Vis Sci. 2015;56(6):3967-3975.

5. Puell MC, Pérez-Carrasco MJ, Hurtado-Ceña FJ, Álvarez-Rementería L. Disk halo size measured in individuals with monofocal versus diffractive multifocal intraocular lenses. J Cataract Refract Surg. 2015;41(11): $2417-2423$.

6. Kretz FT, Breyer D, Klabe K, et al. Clinical Outcomes After Implantation of a Trifocal Toric Intraocular Lens. J Refract Surg. 2015;31(8): 504-510.

7. Law EM, Aggarwal RK, Kasaby H. Clinical outcomes with a new trifocal intraocular lens. Eur J Ophthalmol. 2014;24(4):501-508.

8. Muñoz G, Albarrán-Diego C, Ferrer-Blasco T, Sakla HF, García-Lázaro S. Visual function after bilateral implantation of a new zonal refractive aspheric multifocal intraocular lens. $J$ Cataract Refract Surg. 2011;37(11):2043-2052.

9. Esteve-Taboada JJ, Domínguez-Vicent A, del Águila-Carrasco AJ, Ferrer-Blasco T, Montés-Micó R. Effect of Large Apertures on the Optical Quality of Three Multifocal Lenses. J Refract Surg. 2015;31(10): 666-676.

10. Zettl S, Reiß S, Terwee T, Guthoff RF, Beck R, Stachs O. Effect of pseudophacic mini-monovision as an option for independence of spectacles in everyday life. Klin Monbl Augenheilkd. 2014;231(12): 1196-1202.

11. Labiris G, Giarmoukakis A, Patsiamanidi M, Papadopoulos Z, Kozobolis VP. Mini-monovision versus multifocal intraocular lens implantation. J Cataract Refract Surg. 2015;41(1):53-57.

12. Wilkins MR, Allan BD, Rubin GS, et al. Randomized trial of multifocal intraocular lenses versus monovision after bilateral cataract surgery. Ophthalmology. 2013;120(12):2449-2455.
13. Zhang F, Sugar A, Jacobsen G, Collins M. Visual function and spectacle independence after cataract surgery: bilateral diffractive multifocal intraocular lenses versus monovision pseudophakia. $J$ Cataract Refract Surg. 2011;37(5):853-858.

14. Zhang F, Sugar A, Jacobsen G, Collins M. Visual function and patient satisfaction: Comparison between bilateral diffractive multifocal intraocular lenses and monovision pseudophakia. $J$ Cataract Refract Surg. 2011;37(3):446-453.

15. Finkelman YM, Ng JQ, Barrett GD. Patient satisfaction and visual function after pseudophakic monovision. J Cataract Refract Surg. 2009;35(6):998-1002.

16. Mendicute J, Kapp A, Lévy P, et al. Evaluation of visual outcomes and patient satisfaction after implantation of a diffractive trifocal intraocular lens. J Cataract Refract Surg. 2016;42(2):203-210.

17. Kretz FT, Gerl M, Gerl R, Müller M, Auffarth GU, ZKB00 Study Group. Clinical evaluation of a new pupil independent diffractive multifocal intraocular lens with a $+2.75 \mathrm{D}$ near addition: a European multicentre study. Br J Ophthalmol. 2015;99(12):1655-1659.

18. Frieling-Reuss EH. Comparative analysis of the visual and refractive outcomes of an aspheric diffractive intraocular lens with and without toricity. J Cataract Refract Surg. 2013;39(10):1485-1493.

19. Gil MA, Varon C, Rosello N, Cardona G, Buil JA. Visual acuity, contrast sensitivity, subjective quality of vision, and quality of life with 4 different multifocal IOLs. Eur J Ophthalmol. 2012;22(2):175-187.

20. de Vries NE, Webers CA, Touwslager WR, et al. Dissatisfaction after implantation of multifocal intraocular lenses. J Cataract Refract Surg. 2011;37(5):859-865.

21. Lubiński W, Gronkowska-Serafin J, Podborączyńska-Jodko K. Clinical outcomes after cataract surgery with implantation of the Tecnis ZMB00 multifocal intraocular lens. Med Sci Monit. 2014;20:1220-1226.

22. Kamiya K, Hayashi K, Shimizu K, et al. Multifocal intraocular lens explantation: a case series of 50 eyes. Am J Ophthalmol. 2014;158(2): 215-220.
Clinical Ophthalmology

\section{Publish your work in this journal}

Clinical Ophthalmology is an international, peer-reviewed journal covering all subspecialties within ophthalmology. Key topics include: Optometry; Visual science; Pharmacology and drug therapy in eye diseases; Basic Sciences; Primary and Secondary eye care; Patient Safety and Quality of Care Improvements. This journal is indexed on Submit your manuscript here: http://www.dovepress.com/clinical-ophthalmology-journal

\section{Dovepress}

PubMed Central and CAS, and is the official journal of The Society of Clinical Ophthalmology (SCO). The manuscript management system is completely online and includes a very quick and fair peer-review system, which is all easy to use. Visit http://www.dovepress.com/ testimonials.php to read real quotes from published authors. 